\title{
Nam Dia long, a Vietnamese folk formula, induces apoptosis in MCF-7 cells through various mechanisms of action
}

\author{
My-Nuong Thi Nguyen ${ }^{2}$ and Thuy-Duong Ho-Huynh ${ }^{1 *}$
}

\begin{abstract}
Background: The holistic approach of traditional medicine renders the identification of its mechanisms of action difficult. Microarray technology provides an efficient way to analyze the complex genome-wide gene expression of cells treated with mixtures of medicinal ingredients. We performed transcriptional profiling of MCF-7 cells treated with Nam Dia Long (NDL), a Vietnamese traditional formula, to explore the mechanism of action underlying the apoptosis inducing effect of this formula reported in a previous study.

Methods: MCF-7 cells were treated with aqueous extracts of NDL at the $\mathrm{IC}_{50}$ concentration for 24,36 and $48 \mathrm{~h}$. Total RNAs at $24 \mathrm{~h}$ and $48 \mathrm{~h}$ were subsequently extracted, reverse transcribed and submitted to microarray expression profiling using the Human HT-12 v4.0 Expression Bead Chip (Illumina). Functional analyses were performed using the Database for Annotation, Visualization and Integrated Discovery and the Ingenuity Pathways Analysis. The expression level from selected genes at the three time points were assessed by quantitative real-time RT-PCR and Western blot.

Results: Fifty-four and 601 genes were differentially expressed at 24 and 48 h of NDL treatment, respectively. Genes with altered expression at $24 \mathrm{~h}$ were mostly involved in cell responses to xenobiotic stress whereas genes differentially expressed at $48 \mathrm{~h}$ were related to endoplasmic reticulum stress, DNA damage and cell cycle control. Apoptosis of NDL treated MCF-7 cells resulted from a combination of different mechanisms including the intrinsic and extrinsic pathways, cell cycle arrest- and oxidative stress-related cell death.
\end{abstract}

Conclusion: NDL elicited a two-stage response in MCF-7 treated cells with apoptosis as the ultimate result. The various mechanisms inducing apoptosis reflected the complexity of the formula composition.

Keywords: Traditional medicine, Breast cancer, Apoptosis, Microarray profiling, Nam Dia long

\section{Background}

Traditional medicine (TM) has been present in Vietnam for several thousand years, and was mostly based on the use of the local flora and fauna for disease prevention and treatment. Vietnamese traditional medicine, influenced by Traditional Chinese Medicine, employs a holistic and synergistic approach depending on the use of multiingredients formulae. Despite examples of successful treatment by TM, lack of scientific evidences, especially molecular mechanism of action, seriously hampered its development in the healthcare system [1]. Because of the

\footnotetext{
* Correspondence: hhtduong@hcmus.edu.vn

${ }^{1}$ Department of Genetics, Faculty of Biology and Biotechnology, University of Science, VNU-HCM, 227 Nguyen Van Cu Street, Ward 4, District 5, Ho Chi Minh City, Vietnam

Full list of author information is available at the end of the article
}

holistic nature of TM, the identification of combined effects toward multiple molecular targets of multiingredients formulae poses a serious technological challenge. The microarray technology associated with data mining software constitutes a valuable tool for genomewide analysis of molecular pathways underlying biological effects of TM [2]. Microarray-based transcriptional profiling was used in several studies to unravel the complex therapeutic effects of medicinal plants and traditional remedies [3, 4]. Molecular pathways activated or inhibited and genes modulated by TM treatment provide insights into its mechanisms of action.

Breast cancer is the leading cause of cancer mortality in women worldwide. It is the most frequently diagnosed malignancy in Vietnamese women over the last two 
decades [5]. Chemotherapeutic drugs for breast cancer varied depending on the cancer subtypes and other factors but have in common serious adverse effects on treated patients. TM, as an adjuvant therapy, may contribute to enhance the effectiveness of radiotherapy and chemotherapy while reducing the unwanted side effects. Some successful clinical trials for the treatment of breast cancer based on Traditional Chinese Medicine were reported, but the clinical effectiveness was not properly evaluated [6].

In a previous study, we founded that Nam Dia Long (NDL), a Vietnamese traditional formula empirically prescribed for the treatment of arthritis and some cancers, exhibited higher cytotoxicity on three cancer cell lines, MCF-7, Hep G2 and NCI-H460, compared to normal fibroblasts. This selective cytotoxicity was particularly important on MCF-7 cells, an estrogen-sensitive human breast cancer cell lines. Our results showed that NDL induced apoptosis on MCF-7 cells. Our results also indicated that synergistic interactions among four ingredients of the formula led to its overall biological activities [7]. In this study, we performed a microarray-based transcriptional profiling of MCF-7 cells treated with NDL for different periods of time. Selected genes identified from microarray data that were involved in cell responses leading to apoptosis were furtherly analyzed at the mRNA and protein levels.

The purpose of this study was to identify the possible mechanisms of action underlying the apoptosis inducing effects of NDL on MCF-7 cells.

\section{Methods}

\section{Cell lines and cell culture}

MCF-7 (HTB-22) cells were purchased from the American Type Culture Collection (ATCC, USA). Cells were cultured at $37^{\circ} \mathrm{C}$ and $5 \% \mathrm{CO}_{2}$ in Eagle's Minimal Essential Medium (EMEM) supplemented with 10\% ( $v / v)$ FBS (Sigma, USA), $2 \mathrm{mM}$ L-glutamine (Sigma, USA), $20 \mathrm{mM}$ HEPES (Sigma, USA), $0.025 \mu \mathrm{g} / \mathrm{mL}$ amphotericin B (Sigma, USA), $100 \mathrm{IU} / \mathrm{mL}$ penicillin G (Sigma, USA), and $100 \mu \mathrm{g} / \mathrm{mL}$ streptomycin (Sigma, USA). Cells used in this study were between passages 4 and 20 .

\section{Preparation of NDL extract}

The NDL formula is composed of four ingredients: earthworm (Pheretima aspergillum), mung bean seed (Vigna radiata (L.) Wilczek), black bean seed (Vigna unguiculata (L.) Walp. subsp. unguiculata) and sweet leaf (Sauropus androgynous (L.) Merr.), all in the form of dried materials. These ingredients were identified and provided by the Traditional Medicine Hospital HCMC (Ho Chi Minh City, Vietnam). The quantity of NDL equivalent to one normal dosage for clinical use included $10 \mathrm{~g}$ earthworm, $20 \mathrm{~g}$ mung bean seed, $20 \mathrm{~g}$ black bean seed and $40 \mathrm{~g}$ sweet leaf in a final volume of $90 \mathrm{~mL}$ decoction. NDL extract was prepared as previously described [7]. To obtain a sufficient amount of material for all experiments performed in this study, a large quantity of NDL ingredients equal to many clinical doses was soaked in water for $20 \mathrm{~min}$, boiled for $3 \mathrm{~h}$ in an automatic herbal extractor to obtain aqueous extract and lyophilized to obtain the dried powder. The extract yield of NDL was $0.08 \mathrm{~g} / \mathrm{g}$ of dried material. Dried powders were stored at $-80{ }^{\circ} \mathrm{C}$. Before use, powders were dissolved in distilled water and $0.2 \mu \mathrm{m}$ filter sterilized.

\section{RNA preparation}

Cells at a density of $2 \times 10^{6}$ cells in $10 \mathrm{~cm}$-dish were incubated with NDL extracts at the $\mathrm{IC}_{50}$ concentration. After 24-, 36- and $48 \mathrm{~h}$ - incubation, total RNAs were extracted using RNeasy Mini Kit (Qiagen, Germany) according to the manufacturer's protocol. RNA purity and integrity were assessed using a ND-1000 spectrophotometer (NanoDrop, USA) and Agilent 2100 Bioanalyzer (Agilent Technologies, USA). The RNA Integrity Number (RIN) was calculated for each sample, and RNA samples with RIN $>7.0$ were considered for further analysis. The experiment was repeated at least three times.

\section{Microarray analysis}

Microarray analysis was carried out by Macrogen (South Korea). Briefly, $500 \mathrm{ng}$ of total RNA were amplified and purified using TargetAmp-Nano Labeling Kit for Illumina Expression BeadChip (Epicentre, USA) to yield biotinylated cRNA according to the manufacturer's instructions. After that, $750 \mathrm{ng}$ of labeled cRNA samples were hybridized to each Human HT-12 v4.0 Expression Beadchip (47,000 probes, Illumina, USA) for $18 \mathrm{~h}$ at $58{ }^{\circ} \mathrm{C}$, according to the manufacturer's instructions. The signal was detected using Amersham fluorolink streptavidin-Cy3 (GE Healthcare Bio-Sciences, UK) following the bead array manual. The quality of hybridization and overall chip performance were monitored by visual inspection of both internal quality control checks and the raw scanned data. Raw data were extracted using the software provided by the manufacturer (Illumina Genome Studio v2011.1 (Gene Expression Module v1.9.0)) and transformed by logarithm and normalized by quantile method. Local-pooled-error (LPE) test and fold change (fc) were used to identified significant differentially expressed genes. False discovery rate (FDR) was controlled by adjusting $p$ value using Benjamini-Hochberg algorithm. Briefly, gene expression measured by probes with $\mathrm{fc} \geq 2 \& p<0.05 \&$ fail.count $<6$ probes was considered differential.

The Gene-Enrichment and Functional Annotation analysis for significant probe list was performed using DAVID Bioinformatics Resources 6.7 NIAID/NIH (http://david.abcc.ncifcrf.gov/home.jsp). The GO categories with $p<$ 
$0.01, \mathrm{FDR}<0.05$ and fold enrichment $>1.5$ were considered significant. The Ingenuity Pathways Analysis (IPA, Ingenuity Systems, http://www.ingenuity.com) was used to identify the canonical pathways and upstream regulators modulated by NDL treatment. Pathways with cut-off $p \leq 0.01$ (identified by right-tailed Fisher's exact test and Benjamini-Hochberg multiple testing correction) were considered for further analysis. A z-score value was used to assess the activation state of upstream regulators. A zscore value $>2$ or $<-2$ defined a statistically significant activated or inhibited status, respectively.

\section{Quantitative real-time PCR (qRT-PCR)}

Quantitative real-time RT-PCR was performed as previously described [8]. Briefly, total RNAs were isolated from control and NDL treated MCF-7 cells using Illustra RNAspin mini kit (GE Healthcare Life Sciences, UK) and reverse transcribed into complementary DNA by reverse transcription supermix (Agilent, USA) according to the manufacturer's instruction. Real-time PCR was then performed in a volume of $40 \mu \mathrm{L}$ containing genespecific primers (Additional file 1: Table S1), $1 \mu \mathrm{g}$ cDNA, EvaGreen and PCR master mix (SolGent, South Korea). PCR conditions were as follows: $95^{\circ} \mathrm{C}$ for $15 \mathrm{~min}, 40 \mathrm{cy}$ cles of $95{ }^{\circ} \mathrm{C}$ at $30 \mathrm{~s}, 59{ }^{\circ} \mathrm{C}$ at $30 \mathrm{~s}$, and $72{ }^{\circ} \mathrm{C}$ at $30 \mathrm{~s}$. The relative expression was determined by the $2^{-\Delta \Delta \mathrm{Ct}}$ method with GAPDH as internal control [9]. The statistical differences between the treated and control cells were determined by two-tail paired Student's t-tests through the delta $\mathrm{Ct}$ values.

\section{Western blot analysis}

Control and NDL treated MCF-7 cells were lysed by RIPA buffer (Thermo Scientific Pierce, USA) containing a protease inhibitor cocktail (Complete Protease Inhibitor Cocktail Tablets, Roche Diagnostics GmbH, USA). Protein supernatants were collected by centrifugation at $14,000 \mathrm{rpm}$ for $15 \mathrm{~min}, 4^{\circ} \mathrm{C}$. Protein concentration was measured by BCA Protein Assay kit (Thermo Scientific Pierce, USA). Equal amounts of cell lysate proteins were separated by SDS PAGE and transferred onto nitrocellulose membranes. After blocking by $5 \%$ skim milk in PBS (phosphate buffered saline), membranes were incubated overnight at $4{ }^{\circ} \mathrm{C}$ with primary antibodies (Santa Cruz, USA). Membranes were subsequently rinsed five times with $0.1 \%$ Tween in PBS, and incubated with horseradish peroxidase-conjugated secondary antibody (1: 5000) (Santa Cruz, USA) for $1 \mathrm{~h}$ at room temperature. Finally, membranes were washed five times with $0.1 \%$ Tween in PBS. Protein signals were visualized by SuperSignal West Pico Chemiluminescent Substrate (Thermo Scientific Pierce, USA) and scanned by ImageQuant LAS 500 (GE Healthcare Bio-Sciences, UK).

\section{Statistical analysis}

Values were given as mean \pm SD. Data were represented as averages of independentexperiments performed in triplicate and processed with GraphPad Prism 5 biostatistics software.

\section{Results}

MCF-7 cells were treated with NDL at the $\mathrm{IC}_{50}$ concentration and collected at $24 \mathrm{~h}$ and $48 \mathrm{~h}$ after treatment for microarray analysis. Microarray data were processed using DAVID for Gene-Enrichment and Functional Annotation analysis, and the IPA for the identification of canonical pathways and upstream regulators. The validation of microarray data was performed by semiquantitative PCR on five genes with varied profiles of differential expression. Our attention was furtherly focused on differentially expressed genes at $48 \mathrm{~h}$ which were closely involved in apoptosis induction of NDL treated MCF-7 cells. The expression of these genes was analyzed by qRT-PCR and Western blotting from MCF7 cells treated with NDL for $24 \mathrm{~h}, 36 \mathrm{~h}$, and $48 \mathrm{~h}$.

\section{Identification of differentially expressed genes}

From the microarray data, we assessed the treatment effects of NDL on MCF-7 cells by comparing treated to control cells. Applying cut-offs of $p<0.01$ and fold change $\geq 2$, genes with significant differential expression at $24 \mathrm{~h}$ and $48 \mathrm{~h}$ were identified. At $24 \mathrm{~h}, 44$ and 10 genes were upregulated and downregulated, respectively. At $48 \mathrm{~h}$, the number of genes upregulated and downregulated was 331 and 270, respectively (Additional file 2: Table S2). The top 10 differentially expressed genes at $24 \mathrm{~h}$ and $48 \mathrm{~h}$ treatment were showed in Table 1.

The panel of genes upregulated at $24 \mathrm{~h}$, such as AKR1C4, AKR1C3, AKR1C2, CYP1A1, was mainly involved in xenobiotic metabolism. The most up-regulated genes at $48 \mathrm{~h}$ included FAM129A, GDF-15, DDIT3, HSPA6, LCN2, AKR1C3, AKR1C4, CYP1A1, and F7. The most down-regulated gene at $24 \mathrm{~h}$ and $48 \mathrm{~h}$ was TXNIP. Other genes such as IL8, ANGPTL4, ADM were upregulated at $24 \mathrm{~h}$ followed by a downregulation at $48 \mathrm{~h}$ (Table 2). The majority of genes differentially expressed at $48 \mathrm{~h}$ also displayed altered expression at both time points (Table 2, Additional file 3: Table S3). These genes were mostly ER stress-related (FAM129A, GDF-15, DDIT3, HSPA6) and oxidative-related (LCN2, ANGPTL4, IL8, TXNIP), whose induction may regulate cell proliferation and apoptosis.

Fam129A (NIBAN) is upregulated in response to ER stress and can modulate cell death signaling through positively regulating protein synthesis [10]. The growth differentiation factor 15 (GDF15), a member of the transforming growth factor $\beta$ superfamily, is induced by diverse cellular stress signals. GDF15 can have opposite 
Table 1 Top 10 differentially expressed genes at $24 \mathrm{~h}$ and $48 \mathrm{~h}$ treatment

\begin{tabular}{|c|c|c|c|c|c|c|c|}
\hline \multicolumn{4}{|c|}{ Upregulation } & \multicolumn{4}{|c|}{ Downregulation } \\
\hline \multicolumn{2}{|l|}{$24 \mathrm{~h}$} & \multicolumn{2}{|l|}{$48 \mathrm{~h}$} & \multicolumn{2}{|l|}{$24 \mathrm{~h}$} & \multicolumn{2}{|l|}{$48 \mathrm{~h}$} \\
\hline Gene & Fold change & Gene & Fold change & Gene & Fold change & Gene & Fold change \\
\hline AKR1C4 & $11.81 \pm 0.28$ & FAM129A & $18.46 \pm 0.25$ & TXNIP & $-4.17 \pm 0.65$ & TXNIP & $-12.75 \pm 0.43$ \\
\hline AKR1C3 & $9.15 \pm 0.18$ & GDF15 & $15.70 \pm 0.27$ & GPER & $-3.10 \pm 0.25$ & AFAP1L2 & $-5.26 \pm 0.32$ \\
\hline AKR1C2 & $7.44 \pm 0.21$ & DDIT3 & $14.73 \pm 0.32$ & KCNK12 & $-2.79 \pm 0.78$ & ID3 & $-4.52 \pm 0.38$ \\
\hline FGB & $5.72 \pm 0.73$ & FL35767 & $14.48 \pm 0.22$ & AFAP1L2 & $-2.56 \pm 0.34$ & EFEMP1 & $-4.27 \pm 0.38$ \\
\hline CYP1A1 & $5.30 \pm 0.22$ & HSPA6 & $14.23 \pm 0.49$ & SAMD11 & $-2.45 \pm 0.24$ & NUDT1 & $-4.21 \pm 0.18$ \\
\hline GDF15 & $4.50 \pm 0.20$ & LCN2 & $12.99 \pm 0.27$ & KCNJ8 & $-2.39 \pm 0.23$ & ID1 & $-4.05 \pm 0.51$ \\
\hline FGG & $4.43 \pm 0.48$ & AKR1C3 & $12.88 \pm 0.31$ & EFEMP1 & $-2.29 \pm 0.29$ & CCL2 & $-4.02 \pm 0.38$ \\
\hline ADM & $4.18 \pm 0.50$ & AKR1C4 & $11.33 \pm 0.30$ & ID1 & $-2.12 \pm 0.75$ & GPER & $-3.99 \pm 0.20$ \\
\hline RASD1 & $4.15 \pm 0.78$ & CYP1A1 & $11.27 \pm 0.23$ & SMAD7 & $-2.02 \pm 0.13$ & ELOVL2 & $-3.91 \pm 0.19$ \\
\hline $\mathrm{ABCC} 3$ & $4.11 \pm 0.44$ & F7 & $10.84 \pm 0.20$ & ID3 & $-2.00 \pm 0.50$ & KCNJ8 & $-3.88 \pm 0.19$ \\
\hline
\end{tabular}

Each value represents mean \pm SD $(n=3)$

Table 2 Top differentially expressed genes at both time points

\begin{tabular}{|c|c|c|c|}
\hline \multirow[t]{2}{*}{ Symbol } & \multirow[t]{2}{*}{ Name } & \multicolumn{2}{|l|}{ Fold change } \\
\hline & & $24 \mathrm{~h}$ & $48 \mathrm{~h}$ \\
\hline \multicolumn{4}{|c|}{ Upregulated at $24 \mathrm{~h}$ and $48 \mathrm{~h}$} \\
\hline FAM129A & Family with sequence similarity 129 member A & $1.80 \pm 0.26$ & $18.46 \pm 0.25$ \\
\hline GDF15 & Growth differentiation factor 15 & $4.50 \pm 0.20$ & $15.70 \pm 0.27$ \\
\hline DDIT3 & DNA damage inducible transcript 3 & $2.39 \pm 0.66$ & $14.73 \pm 0.32$ \\
\hline FLJ35767 & & $2.30 \pm 0.42$ & $14.48 \pm 0.22$ \\
\hline HSPA6 & Heat shock protein family A (Hsp70) member 6 & $3.49 \pm 0.28$ & $14.23 \pm 0.49$ \\
\hline LCN2 & Lipocalin 2 & $1.54 \pm 0.40$ & $12.99 \pm 0.27$ \\
\hline AKR1C3 & Aldo-keto reductase family 1 member C3 & $9.15 \pm 0.18$ & $12.88 \pm 0.31$ \\
\hline AKR1C4 & Aldo-keto reductase family 1 member C4 & $11.81 \pm 0.28$ & $11.33 \pm 0.30$ \\
\hline CYP1A1 & Cytochrome P450 family 1 subfamily A member 1 & $5.30 \pm 0.22$ & $11.27 \pm 0.23$ \\
\hline F7 & Coagulation factor VII & $1.65 \pm 0.10$ & $10.84 \pm 0.20$ \\
\hline \multicolumn{4}{|c|}{ Down-regulated at $24 \mathrm{~h}$ and $48 \mathrm{~h}$} \\
\hline TXNIP & Thioredoxin-interacting protein & $-4.17 \pm 0.65$ & $-12.75 \pm 0.43$ \\
\hline AFAP1L2 & Actin filament associated protein 1 like 2 & $-2.56 \pm 0.34$ & $-5.26 \pm 0.32$ \\
\hline ID3 & Inhibitor of DNA binding 3 & $-2.00 \pm 0.50$ & $-4.52 \pm 0.38$ \\
\hline EFEMP1 & EGF containing fibulin like extracellular matrix protein 1 & $-2.29 \pm 0.29$ & $-4.27 \pm 0.38$ \\
\hline NUDT1 & Nudix hydrolase 1 & $-1.52 \pm 0.08$ & $-4.21 \pm 0.18$ \\
\hline ID1 & Inhibitor of DNA binding 1 & $-2.12 \pm 0.75$ & $-4.05 \pm 0.51$ \\
\hline KCNJ8 & Potassium voltage-gated channel subfamily J member 8 & $-2.39 \pm 0.23$ & $-3.88 \pm 0.19$ \\
\hline GPER & The G-protein-coupled estrogen receptor-1 & $-3.10 \pm 0.25$ & $-3.41 \pm 0.17$ \\
\hline ID2 & Inhibitor of DNA binding 2 & $-1.84 \pm 0.23$ & $-3.13 \pm 0.20$ \\
\hline \multicolumn{4}{|c|}{ Up-regulated at $24 \mathrm{~h}$, down-regulated at $48 \mathrm{~h}$} \\
\hline ANGPTL4 & Angiopoietin-like 4 & $2.74 \pm 0.40$ & $-2.72 \pm 0.35$ \\
\hline IL8 & Interleukin-8 & $2.72 \pm 0.61$ & $-2.56 \pm 0.36$ \\
\hline ADM & Adrenomedullin & $4.18 \pm 0.50$ & $-1.84 \pm 0.61$ \\
\hline
\end{tabular}

Each value represents mean $\pm \operatorname{SD}(n=3)$ 
effects, antitumorigenic or tumorigenic, depending on cell types, disease stage or microenvironment. As an antitumoral factor, GFD15 is an important downstream target of p53, inhibits cell growth and induces apoptosis in various tumor cells including MCF-7 cells [11]. An upregulation of NIBAN and GDF15 expression at $24 \mathrm{~h}$ that was furtherly increased at $48 \mathrm{~h}$ suggested an important increasing pression of ER stress in NDL treated MCF-7 cells. DDIT3 is a transcription factor with a majority of target genes involved in cell migration, cell cycle control and apoptosis induction [12]. DDIT3 is upregulated in response to various stress conditions, and is a key mediator of ER-induced cell death. The overexpression of DDIT3 and the decreased expression of BCL2, its downstream target, observed in this study were probably responsible of antiproliferative and apoptotic effects of NDL on MCF-7 cells. LCN2 is a multi-faceted protein with contrasting effects on tumorigenesis and metastasis depending on species and cell lineages specific responses [13]. LCN2 activities were attributed to its iron scavenging properties that can attenuate iron-related oxidative stress [14]. The coagulation factor VII (F7) participates in maintaining vascular hemostasis and promotes breast cancer cell proliferation, invasion and metastasis [15]. The overexpression of LCN2 and F7 observed in this study suggested a protective effect of NDL on MCF-7 cells. Among the downregulated genes in this study, thioredoxin-interacting protein (TXNIP) had the most decreased expression with a fold change $>3$. TXNIP is induced by ER stress and regulates the activity of protein disulfide isomerases (PDIs). It binds to PDIs and increases PDIs activity thus is a feedback regulator of UPR signaling to decrease ER stress [16]. ID1 and ID3 promote angiogenesis during tumor growth. Overexpression of ID1 facilitates the G1 to S phase transition, and induces breast cancer metastasis [17]. NUDT1 is involved in oxidative stress protective mechanism necessary for tumor cells survival since tumors produce large amounts of oxidants [18]. The decreased expression of ID1, ID3, NUDT1 observed in this study had antiproliferative and pro-apoptotic activities whereas TXNIP downregulation could result in protective effect on NDL treated MCF-7 cells. In this study, several genes such as ANGPTL4, IL8, ADM, were upregulated at $24 \mathrm{~h}$ and downregulated at $48 \mathrm{~h}$. ANGPTL4 is a tumor suppressor that inhibits angiogenesis [19]. The inflammatory cytokine IL8 is reported to participate in proliferation, angiogenesis, invasion and metastases during cancer progression [20]. ADM plays important role in apoptosis inhibition, immune escape, and angiogenesis [21]. Up- and downregulated genes induced by NDL on MCF-7 cells at $48 \mathrm{~h}$ displayed opposing activities with a dominance of cell death inducing effect.
In brief, the expression profile of differentially expressed genes at $24 \mathrm{~h}$ and $48 \mathrm{~h}$ suggested an early response for survival followed by apoptotic cell death in NDL treated MCF-7 cells.

\section{Analysis of canonical pathways by IPA}

The GO term analysis was performed for functional classification of the differentially expressed genes between control and NDL treated MCF-7 cells by DAVID. The GO enrichment analysis showed that the common gene set at $24 \mathrm{~h}$ was significantly enriched in cellular responses to xenobiotic stresses. At $48 \mathrm{~h}$, the gene set was significantly enriched in cell cycle-related processes (Additional file 4: Table S4), with few genes involved in protein-related stress.

We subsequently used the IPA software to predict canonical pathways underlying NDL treatment effects on MCF-7 cells. Based on the same cut-off of $p \leq 0.01$, the IPA identified 27 and 30 canonical pathways at $24 \mathrm{~h}$ and $48 \mathrm{~h}$, respectively. These pathways were ranked according to the $p$ value in a descending order (Additional file 5: Table S5). The top pathways at $24 \mathrm{~h}$ with $p \leq 0.001$ included those involved in early phase responses to endogenous and exogenous stresses whereas at $48 \mathrm{~h}$ they were mostly related to cell cycle, unfolded protein response and DNA damage (Fig. 1). Interestingly, Estrogen Biosynthesis, Methylglioxal Degradation III, Retinoate Biosynthesis I, the top 3 pathways at $24 \mathrm{~h}$ were found among the last ranked pathways at $48 \mathrm{~h}$. Contrarily, Unfolded Protein Response, Endoplamic Reticulum Stress Pathway and Aryl Carbon Receptor Signaling which were at the last positions at $24 \mathrm{~h}$ were ranked at or near the top at $48 \mathrm{~h}$ (Additional file 5: Table S5). However, pathways at $24 \mathrm{~h}$ were represented by small numbers of genes, and even with a p cut-off $\leq 0.001$, should be interpreted with caution. Some pathways specifically involved in breast cancer were found among canonical pathways predicted by the IPA at $24 \mathrm{~h}$ and $48 \mathrm{~h}$, included Estrogen-Mediated S Phase Entry, Hereditary Breast Cancer Signaling, Breast Cancer Regulation by Stathmin 1, Estrogen Synthesis (Fig. 1 and Additional file 5).

\section{Upstream regulators (URs) predicted by the IPA}

Using cut-offs of $p \leq 0.001$ and $\mathrm{z}$-score $\geq 2$ and $\leq-2$, we obtained a list of 49 URs at $24 \mathrm{~h}$ and 196 URs at $48 \mathrm{~h}$ (Additional file 6: Table S6). The top predicted URs at $24 \mathrm{~h}$ and $48 \mathrm{~h}$ were displayed in Table 3. Doxorubicin, an anthracycline used in breast cancer treatment was predicted for both time points. The key regulator of ER stress TP53 was listed as the first UR at $48 \mathrm{~h}$, followed by CDKN1A, the cyclin-dependent kinase inhibitor. The most inhibited URs at $48 \mathrm{~h}$ predicted by the IPA were RABL6 and ERBB2. RABL6 belongs to the RAB proteins family, considered as the key regulators of intracellular 

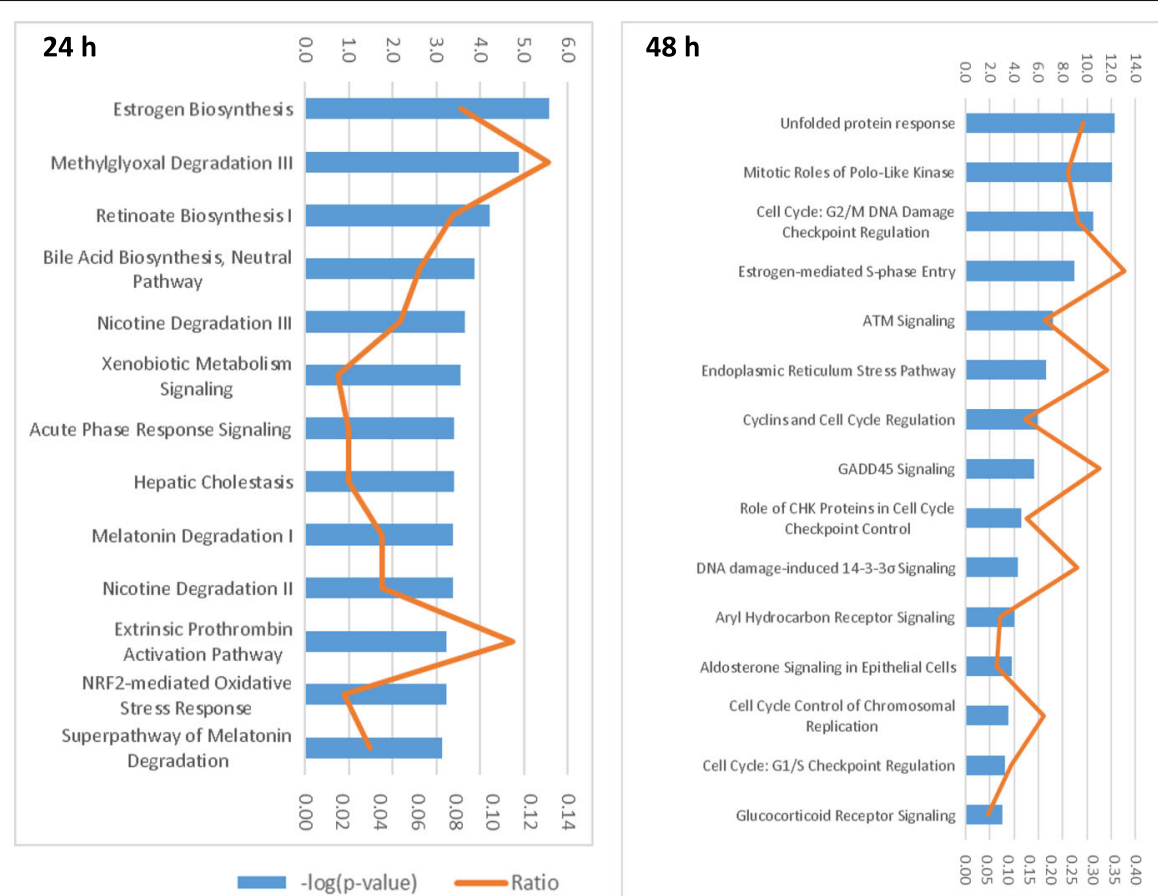

Fig. 1 Top IPA canonical pathways identified at $24 \mathrm{~h}$ and $48 \mathrm{~h}$ after NDL treatment of MCF-7 cells $(p \leq 0.001)$

trafficking that can promote proliferation, migration and invasion of tumor cells through co-ordinating different signaling pathways cross-talk [22]. ERBB2 is a member of the epidermal growth factor family of transmembrane receptors whose overexpression drives oncogenic cell proliferation [23]. Interestingly, thapsigargin, an inhibitor of the sarco/endoplasmic reticulum Ca2+ ATPase (SERCA), was listed as an UR at $24 \mathrm{~h}$ (p 1.5E-05, z-score 2.2) and at $48 \mathrm{~h}$ (p 4.4E-10, z-score 2.9) (Additional file 6). In our previous work, cell growth real-time monitoring of NDL treated MCF-7 cells suggested a mechanism similar to that exerted by thapsigargin [7].

\section{Validation of microarray data by real-time RT-PCR}

To assess the reliability of microarray data, we performed qRT-PCR on five differentially expressed genes including ERN1, GADD45A, BCL2, HMOX1 and ESR1. These genes displayed varied profiles of differential

Table 3 Top URs predicted by the IPA at $24 \mathrm{~h}$ and $48 \mathrm{~h}$ after NDL treatment of MCF-7 cells

\begin{tabular}{|c|c|c|c|c|c|c|c|}
\hline $\begin{array}{l}\text { Upstream } \\
\text { Regulator }\end{array}$ & Molecule Type & $p$ value & z-score & $\begin{array}{l}\text { Upstream } \\
\text { Regulator }\end{array}$ & Molecule Type & $p$-value & z-score \\
\hline $24 \mathrm{~h}$ & & & & $48 \mathrm{~h}$ & & & \\
\hline \multicolumn{8}{|l|}{ Activated } \\
\hline Doxorubicin & chemical drug & $1.2 \mathrm{E}-16$ & 3.32 & TP53 & transcription regulator & $9.8 \mathrm{E}-50$ & 5.38 \\
\hline Cigarette smoke & chemical toxicant & $2.8 \mathrm{E}-15$ & 2.07 & CDKN1A & kinase & $1.3 \mathrm{E}-48$ & 4.11 \\
\hline TNF & cytokine & $1.6 \mathrm{E}-13$ & 2.27 & NUPR1 & transcription regulator & $1.6 \mathrm{E}-32$ & 6.43 \\
\hline Hydrogen peroxide & chemical - endogenous mammalian & $1.9 \mathrm{E}-11$ & 2.07 & Calcitriol & chemical drug & $1.6 \mathrm{E}-30$ & 4.73 \\
\hline NFE2L2 & transcription regulator & $1.0 \mathrm{E}-10$ & 2.68 & Doxorubicin & chemical drug & $6.1 \mathrm{E}-23$ & 3.33 \\
\hline \multicolumn{8}{|l|}{ Inhibited } \\
\hline SFTPA1 & transporter & 4.5E-09 & -2.45 & RABL6 & other & $1.9 \mathrm{E}-38$ & -5.40 \\
\hline Actinomycin D & chemical drug & 4.6E-09 & -2.13 & ERBB2 & kinase & $1.0 \mathrm{E}-29$ & -2.37 \\
\hline $\mathrm{N}$-acetyl-L-cysteine & chemical drug & $1.8 \mathrm{E}-06$ & -2.36 & E2F1 & transcription regulator & $5.4 \mathrm{E}-28$ & -3.41 \\
\hline \multirow[t]{2}{*}{ SB203580 } & chemical - kinase inhibitor & $3.5 \mathrm{E}-06$ & -2.37 & Beta-estradiol & chemical - endogenous mammalian & 7.7E-28 & -2.02 \\
\hline & & & & CSF2 & cytokine & $2.0 \mathrm{E}-27$ & -5.58 \\
\hline
\end{tabular}


expression, up- and downregulation for both time durations or down- followed by upregulation. PCR results showed good correlation with microarray data with some differences in the magnitude of fold change (Table 4).

\section{Effects of NDL on MCF-7 cells gene expression analyzed by real-time RT-PCR and western blot}

We subsequently analyzed 31 genes involved in ER and oxidative stresses, apoptosis, and cell cycle control at $24 \mathrm{~h}, 36 \mathrm{~h}$ and $48 \mathrm{~h}$ at the mRNA and protein levels (Fig. 2 and Fig. 3). MCF-7 cells were treated with NDL at the $\mathrm{IC}_{50}$ dose for 24,36 and $48 \mathrm{~h}$. NDL was replaced by distilled water for the control cells. Total RNAs from control and treated cells were extracted and reverse transcribed. Real-time PCR was performed with genespecific primers. The $2^{-\Delta \Delta C t}$ method was used to assess the relative change in gene expression normalized to GADPH internal control. A t-test $p<0.05$ was considered as significant. Results shown in Fig. 2 and Table 5 were in accordance with those obtained through transcriptional profiling. Furthermore, since an intermediate time point $(36 \mathrm{~h})$ was added for analysis, the kinetic of gene expression alteration of some genes was more precisely defined.

In NDL treated MCF-7 cells, all three arms of the unfolded protein response (UPR) including ERN1, ATF6 and PERK downstream target ATF4 were overexpressed at the three time points, with a sharp increase at $36 \mathrm{~h}$ (Fig. 2). Key ER stress markers such as GRP78, DDIT3 were markedly upregulated at $36 \mathrm{~h}$ and $48 \mathrm{~h}$ (Fig. 2 and Fig. 3). An upregulation of FAM129A at the three time points and a sharp increase of GDF15 expression at $36 \mathrm{~h}$ and $48 \mathrm{~h}$, in accordance with microarray data, indicated an increasing pression of ER stress. Oxidative stress, though less pronounced, was revealed through NFE2L2 upregulation, and particularly through the highly overexpression of HMOX1 gene. NFE2L2, the inducer of many antioxidant proteins, plays important role in driving the expression of antioxidant genes such as FTH1, FTL, HMOX1, AKR, GST [24]. In MCF-7 treated cells, it was slightly up-regulated at $36 \mathrm{~h}$ whereas heme oxygenase- 1
(HMOX1), an endoplasmic reticulum resident protein and NFE2L2 target gene, was increasingly upregulated to reach a 17 -fold change compared to untreated conditions. HMOX1, highly induced under oxidative stress, was shown to exert antiproliferative and proapoptotic effects on some rat and human breast cancer cell lines. Its overexpression also inhibits the invasiveness and migration of breast cancer cells through suppression of matrix metalloproteinase 9 expression [25]. However, the expression of other antioxidative enzyme encoding genes such as CAT, SOD1, SOD2 and GPX-1 decreased at $48 \mathrm{~h}$ of NDL treatment.

The tumor suppressor gene TP53 induces the cyclindependent kinase inhibitor CDKN1A expression leading to an inhibition of cyclin D/CDKs, thus causing a G1 arrest. It can also induce a G2 arrest cell type-specific, and inhibits entry into $S$ phase when the mitotic spindle has been damaged [26]. In p53-dependent gene repression, p21 downregulates genes responsible for cell cycle progression such as CDC25C, CDC2, CHEK1, CCNB1 among others [27]. In this study, the enhanced expression of TP53 and CDKN1A together with progressively down-regulation of genes involved in cell cycle control such as CDK1, CDK2, CCNB, CCNE, CCNA2 from $24 \mathrm{~h}$ to $48 \mathrm{~h}$ suggested an antiproliferative effect of NDL through non-phase specific cell cycle arrest (Fig. 2b).

In NDL treated MCF-7 cells, several apoptosis-related genes displayed significant differential expression including upregulated PUMA, NOXA, TP53, CDKN1A, GADD45A, CAS9, BAX, TRAIL and downregulated BCL2. PUMA, a BCL2 homology 3 (BH3)-only Bcl-2 family member, is transactivated by p53 in response to diverse stimuli including genotoxic stresses such as DNA damage, toxins, proteasome and transcription inhibitors. PUMA promotes mitochondrial outer membrane permeabilization leading to cell death by cooperating with BCL2 effectors BAX and BAK [28]. NOXA, another (BH3)-only protein is a primary p53-response gene. It enhances the oligomerization of BAX or BAK leading to apoptosis induction after DNA damage. The apoptosis inducing effect of NOXA may be more relevant in highly proliferating or malignant versus differentiated, normal cells [29]. After DNA damage,

Table 4 Fold changes in expression of 5 genes obtained from qRT-PCR and microarray data

\begin{tabular}{|c|c|c|c|c|c|c|}
\hline \multirow[t]{2}{*}{ Gene } & \multicolumn{3}{|l|}{ Microarray } & \multicolumn{3}{|l|}{ qRT-PCR } \\
\hline & $24 \mathrm{~h}$ & $48 \mathrm{~h}$ & 24 h/48 h ratio & $24 \mathrm{~h}$ & $48 \mathrm{~h}$ & $24 \mathrm{~h} / 48 \mathrm{~h}$ ratio \\
\hline ERN1 & $1.19 \pm 0.10$ & $2.26 \pm 0.23$ & 1.9 & $1.68 \pm 0.32$ & $2.10 \pm 0.53$ & 1.25 \\
\hline GADD45A & $1.60 \pm 0.10$ & $3.84 \pm 0.07$ & 2.4 & $2.84 \pm 1.17$ & $6.15 \pm 3.43$ & 2.2 \\
\hline CDKN1A & $-1.22 \pm 0.22$ & $2.35 \pm 0.12$ & 2 & $-0.95 \pm 1.98$ & $2.91 \pm 0.69$ & 3 \\
\hline HMOX1 & $3.97 \pm 0.17$ & $10.05 \pm 0.30$ & 2.5 & $5.69 \pm 0.90$ & $17.40 \pm 7.54$ & 3 \\
\hline ESR1 & $-1.33 \pm 0.12$ & $-2.14 \pm 0.11$ & 1.6 & $-1.23 \pm 0.09$ & $-1.66 \pm 0.87$ & 1.3 \\
\hline
\end{tabular}

Each value represents mean $\pm \mathrm{SD}(n=3)$ 

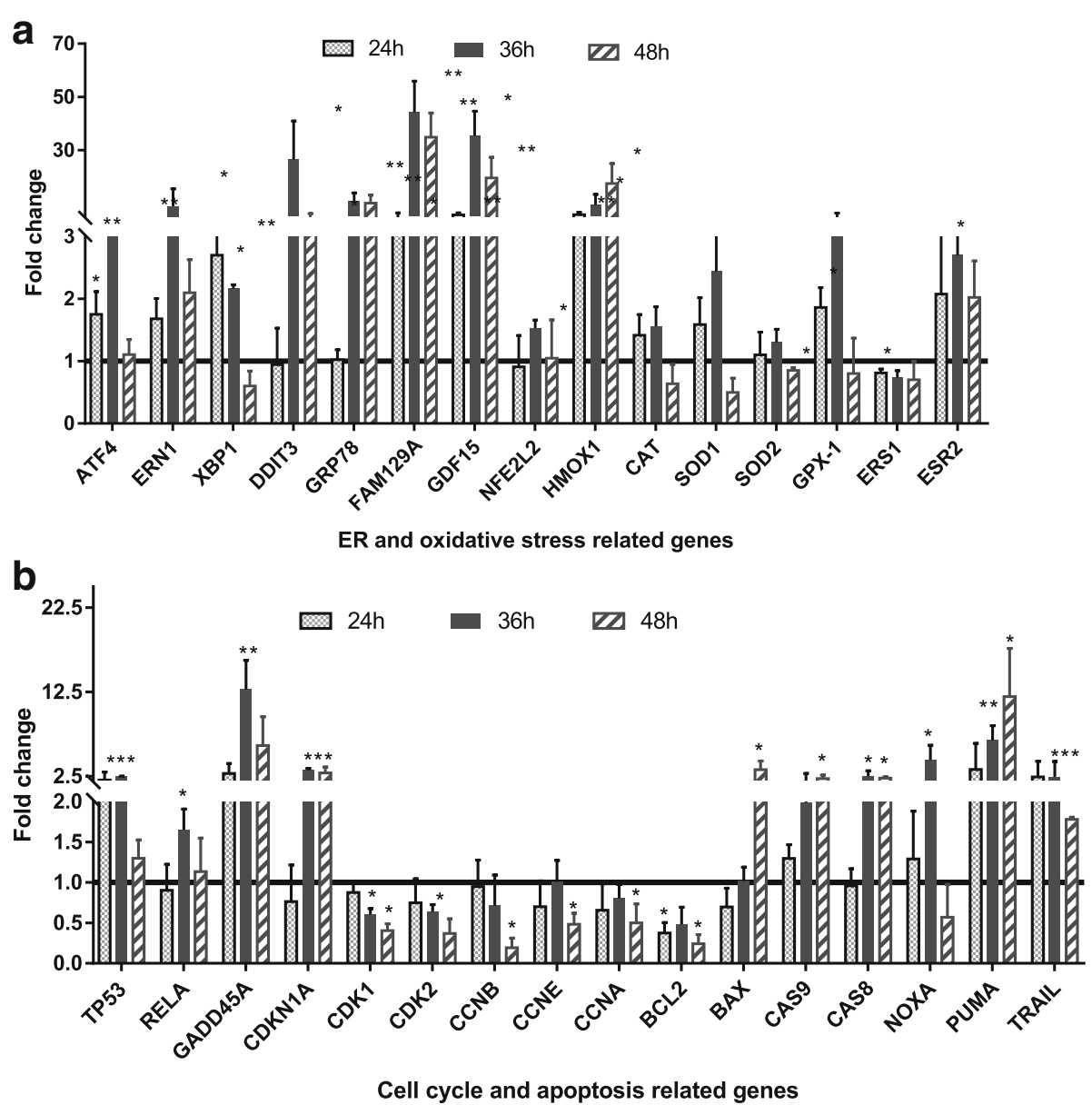

Fig. 2 Real-time RT-PCR analysis of gene expression level after treating MCF-7 cells with NDL for 24, 36 and 48 h. Fold change indicated relative quantitation normalized to GADPH. Fold change $>1$ and $<1$ indicated upregulation and downregulation, respectively. The statistical differences between the treatment and control conditions were analyzed by two-tailed paired Student's t-tests $\left({ }^{*} p<0.05 ;{ }^{* *} p<0.01 ;{ }^{* *} p<0.001\right)$. a, ER and oxidative stress related genes; $\mathbf{b}$, cell cyle and apoptosis related genes

GADD45A family members are upregulated, resulting in cell cycle arrest and apoptosis. GADD45A exerts cell cycle arrest effect by targeting the CDK1/Cyclin B1 complex that is responsible for the G2/M checkpoint. Furthermore, GADD45A proteins can interact with p21 to cause cell cycle arrest at both G1/S and G2/M transitions [30]. BCL2 family proteins control cell survival through preserving the integrity of mitochondrial outer membrane. Pro-apoptotic BCL2 effectors such as BAX and BAK are activated under sustainable cellular stress. In the extrinsic pathway of apoptosis, TRAIL selectively induces apoptosis in various tumor cells over normal cells through interacting with its receptors leading to the activation of caspase 8 and 10 [31]. The overexpression of TRAIL, and an upregulation though not significant of TRAIL-R4 and caspase 8 in this study also suggested a mechanism of extrinsic pathway of apoptosis. Furthermore, estrogen receptor alpha was downregulated whereas estrogen receptor beta was upregulated. In estrogen sensitive tissues such as breast, occupancy of ER $\alpha$ is considered as pro-proliferative whereas occupancy of ER $\beta$ is considered as antiproliferative [32]. In brief, the killing effect of NDL on MCF-7 cells resulted from excessive ER stress combined to oxidative stress, cell cycle arrest and apoptosis induction through the intrinsic and the extrinsic pathways.

Western blot analysis of GRP78, CHOP (DDIT3), PUMA, p53, p21, BCL2, cyclin A, cyclin B1 and cyclin $\mathrm{D}$ in NDL treated MCF-7 cells at $24 \mathrm{~h}, 36 \mathrm{~h}$ and $48 \mathrm{~h}$ were consistent with qRT-PCR data (Fig. 3). Key ER stress markers GRP78, CHOP were markedly and progressively upregulated at the three time points. The antiapoptotic protein p53 and its downstream regulators PUMA and p21 were overexpressed whereas antiapoptotic protein BCL2 was underexpressed. The concentration of cyclin A, cyclin D and cyclin B1 decreased progressively from $24 \mathrm{~h}$ to $48 \mathrm{~h}$. 


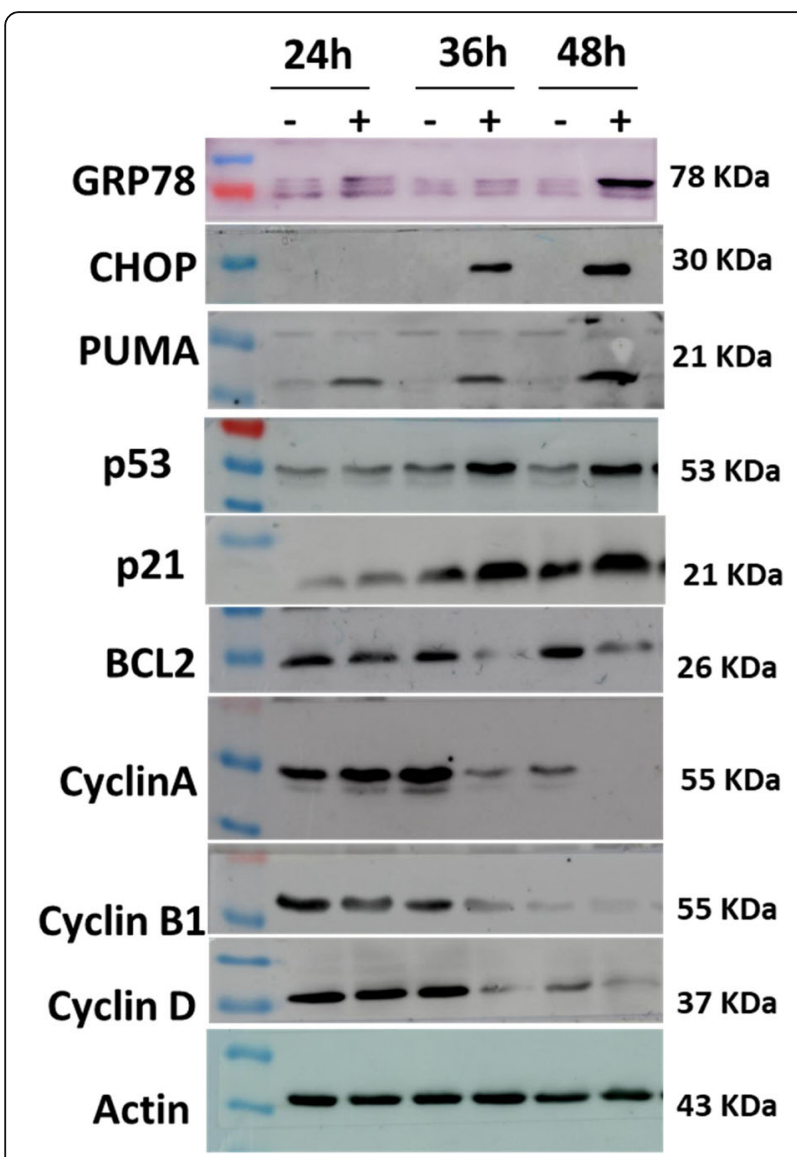

Fig. 3 Western blot analysis of some differentially expressed genes in NDL treated MCF-7 cells

\section{Discussion}

In our previous study, we showed that NDL treatment induced apoptosis on several tumor cell lines, especially MCF-7 cells. The apoptotic inducing effect of NDL resulted from synergistic interactions among different components of the formula and was not cell cycle phase specific [7]. To investigate the molecular mechanisms underlying apoptosis inducing effects of NDL on MCF-7 cells, we profiled a global mRNA expression analysis. Using causal analytics approaches implemented in the IPA, we identified genes and signaling pathways differentially expressed by NDL treated MCF-7 cells. Real-time RT-PCR and Western blot were used to further analyzing important pathways involved in cell death.

\section{NDL elicited a two-phase response in MCF-7 cells}

We analyzed the effects of NDL treatment for different durations of time, $24 \mathrm{~h}, 36 \mathrm{~h}$ and $48 \mathrm{~h}$. Exposure to plant extracts for $24 \mathrm{~h}$ is sufficient to elicit cell responses at the gene expression level [33]. Longer exposure times allowed analysis of the transcriptional cascade that led to the beginning of cell death at $48 \mathrm{~h}$ after NDL treatment [7].
Table 5 Real-time RT-PCR analysis of gene expression level after treating MCF-7 cells with NDL for 24, 36 and $48 \mathrm{~h}$

\begin{tabular}{llll}
\hline Gene & \multicolumn{3}{l}{ Realtime RT-PCR } \\
\cline { 2 - 3 } & $24 \mathrm{~h}$ & $36 \mathrm{~h}$ & $48 \mathrm{~h}$ \\
\hline ER stress & & \\
GRP78 & $1.02 \pm 0.16$ & $10.82 \pm 3.05^{* *}$ & $10.06 \pm 3.05^{* *}$ \\
ERN1 & $1.68 \pm 0.32$ & $8.86 \pm 6.54^{*}$ & $2.10 \pm 0.53^{*}$ \\
ATF4 & $1.75 \pm 0.37^{*}$ & $3.67 \pm 0.61^{* *}$ & $1.11 \pm 0.24$ \\
XBP1 & $2.71 \pm 1.84$ & $2.17 \pm 0.06^{* *}$ & $0.60 \pm 0.24$ \\
DDIT3 & $0.94 \pm 0.59$ & $26.45 \pm 14.47^{*}$ & $4.56 \pm 1.57^{*}$ \\
FAM129A & $4.52 \pm 1.84^{*}$ & $44.20 \pm 11.70^{* *}$ & $34.84 \pm 9.14^{* *}$ \\
GDF15 & $5.65 \pm 0.72^{* *}$ & $35.36 \pm 9.23^{*}$ & $19.49 \pm 7.78^{* *}$ \\
p53 pathway & & & \\
TP53 & $2.06 \pm 0.95$ & $2.46 \pm 0.05^{* * *}$ & $1.30 \pm 0.23$ \\
RELA & $0.90 \pm 0.32$ & $1.65 \pm 0.26^{*}$ & $1.14 \pm 0.41$ \\
GADD45A & $2.84 \pm 1.17$ & $12.82 \pm 3.45^{* *}$ & $6.15 \pm 3.43^{*}$ \\
CDKN1A & $0.76 \pm 0.46$ & $3.26 \pm 0.17^{* * *}$ & $2.91 \pm 0.69^{*}$ \\
Cell cycle & & & \\
CDK1 & $0.88 \pm 0.12$ & $0.61 \pm 0.07^{*}$ & $0.41 \pm 0.08^{*}$ \\
CDK2 & $0.75 \pm 0.29$ & $0.64 \pm 0.08^{*}$ & $0.37 \pm 0.18$ \\
CCNB & $0.95 \pm 0.33$ & $0.71 \pm 0.38$ & $0.19 \pm 0.12^{*}$ \\
CCNE & $0.70 \pm 0.32$ & $1.01 \pm 0.26$ & $0.48 \pm 0.13^{*}$ \\
CCNA2 & $0.66 \pm 0.33$ & $0.81 \pm 0.17$ & $0.50 \pm 0.24^{*}$
\end{tabular}

Apoptosis

$\begin{array}{llll}\text { BCL2 } & 0.37 \pm 0.12^{*} & 0.48 \pm 0.21 & 0.25 \pm 0.11^{*} \\ \text { BAX } & 0.70 \pm 0.23 & 1.02 \pm 0.17 & 3.28 \pm 1.03^{*} \\ \text { CAS9 } & 1.30 \pm 0.17 & 1.99 \pm 0.87 & 2.23 \pm 0.44^{*} \\ \text { CAS8 } & 0.96 \pm 0.21 & 2.52 \pm 0.62^{*} & 2.30 \pm 0.14^{*} \\ \text { NOXA } & 1.29 \pm 0.59 & 4.43 \pm 1.75^{*} & 0.57 \pm 0.40 \\ \text { PUMA } & 3.31 \pm 3.10 & 6.76 \pm 1.75^{* *} & 11.95 \pm 5.74^{*} \\ \text { TRAIL } & 2.44 \pm 1.87 & 2.44 \pm 1.82 & 1.78 \pm 0.03^{* * *}\end{array}$

Oxidative stress response

$\begin{array}{llll}\text { NFE2L2 } & 0.91 \pm 0.51 & 1.53 \pm 0.13^{*} & 1.05 \pm 0.61 \\ \text { HMOX1 } & 5.69 \pm 0.90^{* *} & 9.37 \pm 3.96^{*} & 17.40 \pm 7.54^{*} \\ \text { CAT } & 1.41 \pm 0.33 & 1.56 \pm 0.31 & 0.64 \pm 0.31 \\ \text { SOD1 } & 1.59 \pm 0.43 & 2.44 \pm 0.95 & 0.50 \pm 0.23 \\ \text { SOD2 } & 1.10 \pm 0.37 & 1.30 \pm 0.21 & 0.85 \pm 0.05^{*} \\ \text { GPX-1 } & 1.87 \pm 0.31^{*} & 3.83 \pm 2.50 & 0.80 \pm 0.57\end{array}$

Estrogen receptor

$\begin{array}{llll}\text { ESR1 } & 0.81 \pm 0.06^{*} & 0.73 \pm 0.11 & 0.70 \pm 0.29 \\ \text { ESR2 } & 2.08 \pm 1.20 & 2.70 \pm 0.61^{*} & 2.03 \pm 0.58\end{array}$

Each value represents mean $\pm \mathrm{SD}(n=3)$. Fold change indicated relative quantitation compared to GADPH. Fold change $>1$ indicates upregulation while fold change $<1$ indicates down regulation. The statistical differences between the treatment and control were analyzed by two-tailed paired Student's t-tests $\left({ }^{*} p<0.05 ;{ }^{* *} p<0.01 ;{ }^{* * *} p<0.001\right)$ 
We observed a two-phase response of treated cells, an early response to xenobiotic stresses at $24 \mathrm{~h}$ and an apoptosis process at $48 \mathrm{~h}$. The top most upregulated genes at $24 \mathrm{~h}$ revealed by microarray analysis including AKR1C4, AKR1C3, AKR1C2, CYP1A1 were involved in xenobiotic metabolism. At $48 \mathrm{~h}$, ER stress- and oxidative-related genes were predominant. The increased expression at mRNA and protein levels of PUMA, NOXA, DDIT3, TRAIL, CAS9, BAX at $36 \mathrm{~h}$ and $48 \mathrm{~h}$ clearly indicated an induction of apoptosis leading to cell death as previously reported [7]. The IPA predicted canonical pathways confirmed these observations. The Methylglyoxal Degradation III, Nicotine Degradation III and II, Xenobiotic Metabolism Signaling identified among the top 10 pathways at $24 \mathrm{~h}$ indicated an effort for xenobiotics elimination essential for cell survival. At $48 \mathrm{~h}$ we observed a predominance of pathways related to ER stress, UPR, DNA damage and cell cycle control; all of them can ultimately lead to apoptosis. Cell cycle: G2/M DNA Damage Checkpoint Regulation, ATM Signaling, GADD45 Signaling, DNA Damage-Induced 14-3-3 $\sigma$ Signaling found among the top 10 pathways identified at $48 \mathrm{~h}$ strongly suggested a major role of DNA damage causing cell death. The ranking position switch between 24 h- (Estrogen Biosynthesis, Methylglioxal Degradation III, Retinoate Biosynthesis I) and $48 \mathrm{~h}$ - (Unfolded Protein Response, Endoplamic Reticulum Stress Pathway and Aryl Carbon Receptor Signaling) predicted pathways also indicated an early survival response of treated cells which was further replaced by apoptosis induction. Different cell cycle phase related pathways identified at $48 \mathrm{~h}$ such as Mitotic Roles of PoloLike Kinases, Cell Cycle:G2/M DNA Damage Checkpoint Regulation (activated), Cyclins and Cell Cycle Regulation, Role of CHK Proteins in Cell Cycle Regulation, Cell Cycle: G1/S Checkpoint Regulation (activated) indicated a non-phase specific arrest effect of NDL on MCF-7 cells as previously reported [7]. Interestingly, Estrogene Biosynthesis, the first ranked pathway at $24 \mathrm{~h}$, exhibited less importance at $48 \mathrm{~h}$ whereas Estrogen-Mediated SPhase Entry (ranked at position 4) was clearly inhibited at $48 \mathrm{~h}$ (Additional file 5: Table S5).

\section{The apoptosis inducing effect of NDL resulted from a combination of mechanisms of action}

The profile of differentially expressed genes at $24 \mathrm{~h}$ and $48 \mathrm{~h}$ revealed different mechanisms of action of NDL on MCF-7 cells, including ER stress, oxidative stress, intrinsic and extrinsic pathways of apoptosis. The ER stress response promotes cell survival by reducing protein synthesis and upregulating chaperones. However, if the UPR persists and ER stress can not be resolved, cells will undergo apoptotic process [34]. ER stress followed by UPR activation were probably the main causes of NDL treated MCF-7 cells apoptosis at $48 \mathrm{~h}$, indicated by differentially expressed key factors including ATF4, CHOP, PUMA, BCL2, ERN1. Apoptosis of treated MCF7 cells was triggered mainly through the mitochondrial intrinsic pathway denoted by the overexpression of numerous key factors such as PUMA, NOXA, BAX, CAS9, BCL2. Besides, an increase of TRAIL and caspase 8 expression at $48 \mathrm{~h}$ suggested the contribution of the extrinsic apoptosis pathway as previously described [35]. The upregulation of NFE2L2 at $36 \mathrm{~h}$ and HMOX1 at the three time points observed in this study also indicated the presence of oxidative stress response. Glucocorticoid Receptor signaling and NRF2-Mediated Oxidative Stress Response, Extrinsic Prothrombin Activation Pathway and Airway Pathology in Chronic Obstructive Pulmonary Disease present at both timing in NDL treated MCF7 cells confirmed a ubiquitous though less pronounced role of oxidative stress. The crosstalk between ER stress and oxidative stress can be mediated by DDIT3, an UPR component which can induce oxidative stress [36]. The upregulation of DDIT3 in this study could play a role in the co-ordination of ER and oxidative stresses in NDL treated cells. The numerous URs identified for $24 \mathrm{~h}$ and $48 \mathrm{~h}$ of NDL treatment highlighted the complex pharmacological effects of NDL on MCF-7 cells. Their mechanisms of action differed and can complement each other. Interestingly, in our previous work, kinetic profile of NDL treated MCF-7 cells growth suggested an effect similar to that of thapsigargin, an inhibitor of the SERCA [7]. IPA analysis in this study predicted thapsigargin as an UR at both time durations with $p$ values of $1.5 \mathrm{E}-05,4.4 \mathrm{E}-10$, respectively and an activation $\mathrm{z}$-score of 2.2 and 2.9, respectively. The inhibition of SERCA by thapsigargin affects the calcium homeostasis and can activate apoptotic pathways causing cell death [37]. NDL selectively induced cell death in MCF-7 cells but not in normal cells as previously shown in our previous work. In this study, we showed that NDL activates the UPR, converting it from cytoprotective to cytotoxic. A possible explanation for the selective cytotoxicity of NDL is that the UPR is already elevated in tumor cells, whereas it is of much lower level in normal cells. Therefore, it is much easier to increase the UPR to a level of conversion in tumor cells as suggested by previous study [38]. The complex pharmacological nature of NDL was also displayed through its effects on genes of opposing activities. CYP1A1, CYP2F1, CYP1B1 were upregulated while TXNIP was downregulated, though all of them were involved in ROS production. An enhanced expression of the antioxidant enzyme $\mathrm{HO}-1$ and down-regulated CAT, SOD 1,2 and GPX were also revealed. These contradictory results probably reflected complicated interactions among NDL ingredients, either synergistic or antagonistic. Nevertheless, NDL seemed to induce a two-phase response in MCF-7 cells, 
a survival phase and an apoptotic phase, depending on exposure times.

\section{Anticancer activities of NDL on MCF-7 cells mimicked the mechanisms of action of some anticancer drugs for breast cancer}

The most similar anticancer drugs to NDL among the top URs predicted were doxorubicin for $24 \mathrm{~h}$; and calcitriol, doxorubicin, fulvestrant, medroxyprogesterone acetate for $48 \mathrm{~h}$ (Additional file 6: Table S6). Among these drugs, doxorubicin, fulvestrant, medroxyprogesterone acetate were FDA-approved drugs for breast cancer treatment.

Calcitriol acting as a steroid hormone regulates the expression of more than 60 target genes including p21, cyclins and CDKs. The upregulation of $\mathrm{p} 21$ by calcitriol accompanied by the reduced expression of cyclins A2, B1, B2, D, D3, E1, F, CDK2 and CDK4 blocks the transition from $\mathrm{G} 1$ to $\mathrm{S}$ phase and initiates the differentiation process. In ER $\alpha$-negative breast cancer cells, calcitriol restores the response to antiestrogen such as tamoxifen and fulvestrant. It may work synergistically with other antineoplastic drugs such as taxanes, alkylating agents, and ionizing radiation [39]. Results from this study showed an increased expression of p21 and decreased expression of some cyclins and cyclin-dependent kinases at the mRNA and protein levels suggesting a mechanism of action similar to calcitriol on MCF-7 cells. Doxorubicin can act in cancer cells through two mechanisms: (1) intercalation into DNA and disruption of topoisomerase II-mediated DNA repair; and (2) free radical generation causing damage to cell membranes and DNA. The first pathway may be modulated by genes involved in the deactivation of free radicals such as glutathione peroxidase (GPX), superoxide dismutase (SOD), catalase while the second mechanism involves genes of the DNA repair system such as p53, TOP2A, and GADD45A. Furthermore, doxorubicin is a p53-dependent downregulator of stathmin (STMN1) [40]. Since high levels of stathmin may confer resistance to antimicrotubule agents [41]; a decreased expression would strengthen therapeutic effects of drugs such as vinblastine. In this study, we observed a decreased expression of CAT (fc -1.23$)$, SOD1 (fc -2.0), SOD2 (fc -1.47), GPX1 (fc -1.25), TOP2A (fc -2.46) and stathmin at $48 \mathrm{~h}$ (fc -2.44). Fulvestrant, an estrogen receptor antagonist, competitively binds to the estrogen receptor and prevents endogenous estrogen effects on target cells. The combination of antiestrogens with antitumor agents has been shown to be more effective at inhibiting breast tumor cell lines than either drugs alone [42].

This study had some limitations. The first, which is common to other transcriptional profiling studies, was the lack of certainty about functional relationships among molecules and pathways revealed through microarray data mining of MCF-7 cells treated with NDL. However, the functional assays performed on selected genes strongly supported the prediction obtained from genome-wide analysis. Another problem involved the lack of a large panel of doses and durations of treatment, especially when dealing with a mixture of extracts that can have synergistic as well as antagonistic interactions depending on the dose and exposure time. Since this study was focused on apoptosis induction effects of NDL, other activities of the formula susceptible for use as an adjuvant therapy, which constituted the strength of traditional medicine, were not investigated. Moreover, the ideal level of UPR signaling to create apoptosis inducing effect instead of an adaptive survival UPR was not determined. Another limitation of this work, inherent to all in vitro studies, involved problems in extrapolating in vitro data to in vivo studies. Drug bioavailability, distribution, metabolism and clearance in in vivo systems as well as the complex interactions with different cell types were not truly reflected in in vitro experiments. However, results in this study did reveal the principal molecular pathways which constituted the targets for future in vivo studies [43].

\section{Conclusion}

Traditional medicine based on the combination of herbs targeting different molecules/pathways may increase therapeutic efficacy and reduces adverse effects. However, traditional formulae probably contain also non-effective, even undesired ingredients or non-appropriate concentration of ingredients. The results of this study showed that NDL formula induced apoptosis on MCF-7 cells through different mechanisms, ER stress being the most important cause of cell death. But results also suggested counteracting actions among the ingredients of NDL formula. Since our previous work showed that the presence of all ingredients is needed for the highest cytotoxic effect, further investigations will be necessary to determine the dosage of each component to create the optimal apoptosis induction effect and microenvironment homeostasis susceptible for use as complementary medicine with conventional therapies.

\section{Additional files}

Additional file 1: Table S1. Primers used for Real-time RT-PCR. (XLSX $12 \mathrm{~kb}$ )

Additional file 2: Table S2. Differentially expressed genes in MCF-7 cells after treatment with NDL at $24 \mathrm{~h}$ and $48 \mathrm{~h}$. (XLSX $45 \mathrm{~kb}$ )

Additional file 3: Table S3. Genes differentially expressed at both $24 \mathrm{~h}$ and $48 \mathrm{~h}$ of treatment with NDL. (XLSX $15 \mathrm{~kb}$ )

Additional file 4: Table S4. The GO term analysis by DAVID of genes differentially expressed by MCF-7 cells treated with NDL. (XLSX 18 kb)

Additional file 5: Table S5. IPA canonical pathways identified at $24 \mathrm{~h}$ and $48 \mathrm{~h}$ from NDL treated MCF-7 cells. (XLSX $17 \mathrm{~kb}$ )

Additional file 6: Table S6. Upstream regulators predicted by the IPA at $24 \mathrm{~h}$ and $48 \mathrm{~h}$ after NDL treatment of MCF-7 cells. (XLSX $36 \mathrm{~kb}$ ) 


\section{Abbreviations}

DAVID: Database for Annotation, Visualization and Integrated Discovery; ER: endoplasmic reticulum; Fc: fold change; FDR: False discovery rate; IPA: Ingenuity Pathways Analysis; NDL: Nam Dia Long; SERCA: sarco/ endoplasmic reticulum Ca2+ ATPase; TM: traditional medicine; UPR: unfolded protein response; UR: upstream regulator

\section{Acknowledgements}

The authors would like to thank Dr. Duong Hong To Quyen (The Traditional Medicine Hospital HCMC) for providing decoction of NDL. We also thank MSc. Bui Hoang Bao Ngoc for her assistance in analyzing data using the IPA. We thank our colleagues from the Laboratory of Molecular Biology for technique assistance and useful discussions.

\section{Funding}

This study was supported by Vietnam National University (VNU-HCM).

\section{Availability of data and materials}

All data generated or analyzed during this study are included in this manuscript and its supplementary information files.

\section{Authors' contributions}

MNTN designed and carried out the study. TDHH participated in the design of the study and supervised the writing of the manuscript. Both authors read and approved the final manuscript.

\section{Ethics approval and consent to participate}

Not applicable

\section{Consent for publication}

Not applicable

\section{Competing interests}

The authors declare that they have no competing interests.

\section{Publisher's Note}

Springer Nature remains neutral with regard to jurisdictional claims in published maps and institutional affiliations.

\section{Author details}

'Department of Genetics, Faculty of Biology and Biotechnology, University of Science, VNU-HCM, 227 Nguyen Van Cu Street, Ward 4, District 5, Ho Chi Minh City, Vietnam. ${ }^{2}$ Molecular Genetics and Genomics Research Group, Cancer Research Laboratory, University of Science, VNU-HCM, Building B6.1, Dong Hoa Village, Di An District, Binh Duong Province, Vietnam.

\section{Received: 23 August 2017 Accepted: 24 November 2017}

\section{Published online: 04 December 2017}

\section{References}

1. Woerdenbag HJ, Nguyen TM, Van Vu D, Tran H, Nguyen DT, Van Tran T, et al. Vietnamese traditional medicine from a pharmacist's perspective. Expert Rev Clin Pharmacol. 2012;5:459-77.

2. Chavan $\mathrm{P}$, Joshi K, Patwardhan B. DNA microarrays in herbal drug research. Evid Based Complement Alternat Med. 2006;3:447-57.

3. Ren G, Fan X, Liang Q, Wang Y, Luo G. Screening and evaluation of traditional Chinese medicine by microarray expression analysis. J Ethnopharmacol. 2013:147:564-9.

4. Wen Z, Wang Z, Wang S, Ravula R, Yang L, Xu J, et al. Discovery of molecular mechanisms of traditional Chinese medicinal formula Si-Wu-tang using gene expression microarray and connectivity map. PLoS One. 2011;6:e18278.

5. Trieu PDY, Mello-Thoms C, Brennan PC. Female breast cancer in Vietnam: a comparison across Asian specific regions. Cancer. Biol Med. 2015;12(3):238-45.

6. Cohen I, Tagliaferri M, Tripathy D. Traditional Chinese medicine in the treatment of breast cancer. Semin Oncol. 2002:29:563-74

7. Nguyen M-NT, Ho-Huynh T-D. Selective cytotoxicity of a Vietnamese traditional formula, Nam Dia long, against MCF-7 cells by synergistic effects. BMC Complement Altern Med. 2016;16:220.

8. Nuong NM, Vy NT, Duong HHT. Combinative effects of Thanh Hao Miet Giap Thang (sweet wormwood and tortoise shell decoction) ingredients on antioxidative activity in vitro. African J Tradit Complement Altern Med. 2014 11:136-41.

9. Livak KJ, Schmittgen TD. Analysis of relative gene expression data using real-time quantitative PCR and the $2(-$ Delta Delta $C(T))$ method. Methods. 2001;25:402-8

10. Sun GD, Kobayashi T, Abe M, Tada N, Adachi H, Shiota A, et al. The endoplasmic reticulum stress-inducible protein Niban regulates elF2a and S6K1/4E-BP1 phosphorylation. Biochem Biophys Res Commun. 2007;360:181-7.

11. Corre J, Hébraud B, Bourin P. Concise review: growth differentiation factor 15 in pathology: a clinical role? Stem Cells Transl Med. 2013;2:946-52.

12. Jauhiainen A, Thomsen C, Strombom L, Grundevik P, Andersson C, Danielsson A, et al. Distinct cytoplasmic and nuclear functions of the stress induced protein DDIT3/CHOP/GADD153. PLoS One. 2012;7:e33208.

13. Li C, Chan YR. Lipocalin 2 regulation and its complex role in inflammation and cancer. Cytokine. 2011;56:435-41.

14. Yamada $Y$, Miyamoto $T$, Kashima H, Kobara H, Asaka R, Ando H, et al. Lipocalin 2 attenuates iron-related oxidative stress and prolongs the survival of ovarian clear cell carcinoma cells by up-regulating the CD44 variant. Free Radic Res. 2016:50:414-25.

15. Lal I, Dittus K, Holmes CE. Platelets, coagulation and fibrinolysis in breast cancer progression. Breast Cancer Res. 2013;15:207.

16. Lee S, Min Kim S, Dotimas J, Li L, Feener EP, Baldus S, et al. Thioredoxininteracting protein regulates protein disulfide isomerases and endoplasmic reticulum stress. EMBO Mol Med. 2014;6:732-43.

17. Ling F, Kang B, Sun X-H. Id Proteins. Curr Top Dev Biol. 2014:189-216.

18. Samaranayake G, Huynh M, Rai P. MTH1 as a Chemotherapeutic Target: The Elephant in the Room. Cancers (Basel). 2017:9:47.

19. Okochi-Takada E, Hattori N, Tsukamoto T, Miyamoto K, Ando T, Ito S, et al. ANGPTL4 is a secreted tumor suppressor that inhibits angiogenesis. Oncogene. 2014;33:2273-8.

20. Singh JK, Simoes BM, Howell SJ, Farnie G, Clarke RB. Recent advances reveal IL-8 signaling as a potential key to targeting breast cancer stem cells. Breast Cancer Res. 2013;15:210.

21. Zhang $Y, X u Y$, Ma J, Pang X, Dong M. Adrenomedullin promotes angiogenesis in epithelial ovarian cancer through upregulating hypoxia-inducible factor-1a and vascular endothelial growth factor. Sci Rep. 2017:7:40524.

22. Recchi C, Seabra MC. Novel functions for Rab GTPases in multiple aspects of tumour progression. Biochem Soc Trans. 2012:40:1398-403.

23. Baselga J, Swain SM. Novel anticancer targets: revisiting ERBB2 and discovering ERBB3. Nat Rev Cancer. 2009:9:463-75.

24. MacLeod AK, MCMahon M, Plummer SM, Higgins LG, Penning TM, Igarash $K$, et al. Characterization of the cancer chemopreventive NRF2-dependent gene battery in human keratinocytes: demonstration that the KEAP1-NRF2 pathway, and not the BACH1-NRF2 pathway, controls cytoprotection against electrophiles as well as redox-cycling compounds. Carcinogenesis. 2009;30:1571-80.

25. Lin C-W, Shen S-C, Hou W-C, Yang L-Y, Chen Y-C. Heme oxygenase-1 inhibits breast cancer invasion via suppressing the expression of matrix metalloproteinase-9. Mol Cancer Ther. 2008;7:1195-206.

26. Pucci B, Kasten M, Giordano A. Cell cycle and apoptosis. Neoplasia. 2000;2 291-9.

27. Abbas T, Dutta A. p21 in cancer: intricate networks and multiple activities. Nat Rev Cancer. 2009:9:400-14.

28. Chipuk JE, Fisher JC, Dillon CP, Kriwacki RW, Kuwana T, Green DR Mechanism of apoptosis induction by inhibition of the anti-apoptotic BCL-2 proteins. Proc Natl Acad Sci. 2008;105:20327-32.

29. Ploner C, Kofler R, Villunger A. Noxa: at the tip of the balance between life and death. Oncogene. 2008;27:S84-92.

30. Tamura RE, de Vasconcellos JF, Sarkar D, Libermann TA, Fisher PB, Zerbini LF. GADD45 proteins: central players in tumorigenesis. Curr Mol Med. 2012; 12:634-51.

31. Wang S, El-Deiry WSTRAIL. Apoptosis induction by TNF-family death receptors. Oncogene. 2003;22:8628-33.

32. Rižner TL. Estrogen metabolism and action in endometriosis. Mol Cell Endocrinol. 2009;307:8-18.

33. Kong KW, Abdul Aziz A, Razali N, Aminuddin N, Mat Junit S. Antioxidant-rich leaf extract of Barringtonia Racemosa significantly alters the in vitro expression of genes encoding enzymes that are involved in methylglyoxal degradation III. PeerJ. 2016;4:e2379.

34. Sano R, Reed JCER. Stress-induced cell death mechanisms. Biochim Biophys Acta. 2013;1833(12):3460-70 
35. Fulda S, Debatin K-M. Extrinsic versus intrinsic apoptosis pathways in anticancer chemotherapy. Oncogene. 2006;25:4798-811.

36. Cao SS, Kaufman RJ. Endoplasmic reticulum stress and oxidative stress in cell fate decision and human disease. Antioxid Redox Signal. 2014;21:396-413.

37. Dubois C, Vanden Abeele F, Sehgal P, Olesen C, Junker S, Christensen SB, et al. Differential effects of thapsigargin analogues on apoptosis of prostate cancer cells. FEBS J. 2013;280:5430-40.

38. Zheng X, Andruska N, Yu L, Mao C, Kim JE, Livezey M, et al. Interplay between steroid hormone activation of the unfolded protein response and nuclear receptor action. Steroids. 2016;114:2-6.

39. Díaz L, Díaz-Munoz M, García-Gaytán A, Méndez I. Mechanistic effects of Calcitriol in cancer biology. Nutrients. 2015;7:5020-50.

40. Ahn J, Murphy M, Kratowicz S, Wang A, Levine AJ, George DL. Downregulation of the stathmin/Op18 and FKBP25 genes following p53 induction. Oncogene. 1999:18:5954-8.

41. Alli E, Bash-Babula J, Yang J-M, Hait WN. Effect of stathmin on the sensitivity to antimicrotubule drugs in human breast cancer. Cancer Res. 2002;62(23): 6864-9

42. Piccart M, Parker LM, Pritchard Kl. Oestrogen receptor downregulation: an opportunity for extending the window of endocrine therapy in advanced breast cancer. Ann Oncol. 2003;14:1017-25.

43. Lin JH. Applications and limitations of interspecies scaling and in vitro extrapolation in pharmacokinetics. Drug Metab Dispos. 1998;26(12):1202-12.

\section{Submit your next manuscript to BioMed Central} and we will help you at every step:

- We accept pre-submission inquiries

- Our selector tool helps you to find the most relevant journal

- We provide round the clock customer support

- Convenient online submission

- Thorough peer review

- Inclusion in PubMed and all major indexing services

- Maximum visibility for your research

Submit your manuscript at www.biomedcentral.com/submit 